\title{
MOLECULAR RECOGNITION SPECIFICITY OF ANTI-3-NITROTYROSINE ANTIBODIES REVEALED BY AFFINITY- MASS SPECTROMETRY AND IMMUNOANALYTICAL METHODS
}

\author{
BRÎNDUŞA-ALINA PETRE, MIHAELA DRĂGUŞANU, \\ AND MICHAEL PRZYBYLSKI ${ }^{*}$ \\ Laboratory of Analytical Chemistry and Biopolymer Structure Analysis, \\ Department of Chemistry, University of Konstanz, Universitätsstrasse 10, \\ 78457 Konstanz, Germany
}

\begin{abstract}
Nitration of tyrosine residues in proteins has been mainly characterised by immunoanalytical methods using anti-3-nitrotyrosine antibodies, and nitration sites and sequences have been hitherto identified only in a few cases using mass spectrometric methods. Immuno-analytical methods frequently suffer from low and poorly characterised detection specificity of antinitrotyrosine antibodies, while mass spectrometric methods for identification of Tyrosine nitration may be hampered by low levels of modification, and by possible changes of structure and proteolytic degradation of proteins introduced by the nitration. Moreover, no detailed, molecular characterisation of the specificity of anti-3-nitrotyrosine antibodies has been reported. In this study we describe a molecular study of the recognition specificities and affinities of two commercially available, monoclonal anti-nitrotyrosine antibodies by affinity-mass spectrometry, using different 3-nitrotyrosine containing peptides. Tyrosine-nitrated and non-nitrated substrate peptides of prostacyclin synthase (PCS), an enzyme inactivated by nitration of the active site Tyr430 residue, were synthesised by solid-phase peptide synthesis (SPPS), purified by reversed phasehigh performance liquid chromatography (RP-HPLC) and characterised by electrospray (ESI) and matrix-assisted laser desorption-ionisation (MALDI) mass spectrometry. Binding affinities and specificities of PCS peptides with different Tyr-nitration sites and sequence mutations adjacent to Tyr- 430 were determined by evaluation of anti-nitrotyrosine antibodies using an affinitymass spectrometry approach, compared to immuno-analytical determination using dot-blot and ELISA. The results showed that the antibodies may discriminate in the recognition of peptides with different $\mathrm{N}$-terminal adjacent sequences to the nitrotyrosine residues, depending on the type of immunogen employed. A quantitative ELISA estimation was developed for the determination of antibody binding by Tyrosine-nitrated peptides.
\end{abstract}

\section{Introduction}

Tyrosine nitration is a covalent protein modification resulting from the addition of a nitro- $\left(\mathrm{NO}_{2}\right)$ group onto one of the two equivalent ortho carbons of the aromatic ring of tyrosine residues. Tyrosine nitration may be the result of an excessive generation of nitric oxide (NO) or its by-products as well as reactive oxygen species

\footnotetext{
${ }^{*}$ Corresponding author. Professor Dr. Michael Przybylski, Department of Chemistry, University of Konstanz; Tel:++49-7531-882249; Fax: ++49-7531-3097; e-mail: Michael.Przybylski@uni-konstanz.de
} 
(ROS). Several mechanisms for tyrosine nitration have been proposed, the two of which most widely advanced to occur in vivo involve (i), the formation of peroxynitrite $(\mathrm{PN})$, and (ii), catalytic nitration via heme-peroxidases [1]. Nitration thus may occur under physiological conditions, but may be substantially enhanced under pathophysiological conditions. Several proteins found to be modified by nitration, have been associated with different disorders such as lung infection [2], inflammation [3,4], Parkinson's [5] and Alzheimer's disease [6], and diabetes [7], all of which have been associated with enhanced oxidative stress.

Specific nitrated tyrosine residues or tyrosine-nitration motifs in a protein should be more specific oxidative biomarkers, than merely the characterisation of overall nitro-tyrosine levels. Several methods have been employed to detect and identify protein tyrosine nitration in both in vitro and in vivo studies. Anti-3-NT antibodies permit detection by immunohistochemistry [8], Western blot [9], or enzyme-linked immunosorbent assay (ELISA) [10,11]. However, these methods do not identify which specific tyrosine residue(s) have been nitrated; moreover, they are frequently limited by low detection specificities of commercial anti-3-NT-antibodies. Only little information on the characterization and properties of different antibodies against 3-nitrotyrosine is available from previous publications [12], and the identification and localization of the sites of nitration in proteins remains a significant methodological challenge. Of the currently available methods, only mass spectrometry (MS) is able to specifically locate 3-nitro-tyrosine sites in proteins due to its sensitivity and molecular specificity. High resolution Fourier-transform- ion cyclotron resonance mass spectrometry (FTICR-MS), in combination with immunoanalytical procedures has been recently developed as a powerful tool for the unequivocal, molecular identification of tyrosine-nitrations, such as upon peroxynitrite treatment at the active site Tyr-430 residue of bovine prostacyclin synthase (PCS) [13]. Detailed structural studies were performed with Tyr-nitrated peptides, prepared by solid phase peptide synthesis (SPPS), using FTICR-MS in combination with CD spectroscopy and structure modelling [14].

In the present study we have characterized two commercially available antibodies raised against different immunogens containing 3-nitrotyrosine (Table 1), with regard to their recognition specificities and affinities to different Tyr-nitrated peptides of prostacycline synthase. Tyr- nitrated and non-nitrated PCS peptides were compared using (i), conventional dot blot and ELISA, and (ii), a newly developed immunoaffinity - mass spectrometric approach as shown in Figure 1. Affinity mass spectrometry methods, in combination with proteolytic digestion, have been previously developed and employed in our laboratory (i), for the identification of antigen- epitopes (epitope- excision and - extraction-MS) [15,16]; and (ii), in an affinity- proteomics approach which enables direct protein identification from biological material with unprecedented selectivity [17,18]. The affinity- MS procedure (see Figure 1) is based on the binding of antigen- peptides to an antibody immobilized on a micro-column; upon removal of unbound material by washings steps, the affinity- bound peptides are specifically dissociated from the column by acidification and analyzed by MS. Using this procedure we have characterized the recognition specificity of anti 3-NT antibodies by mass spectrometry. 


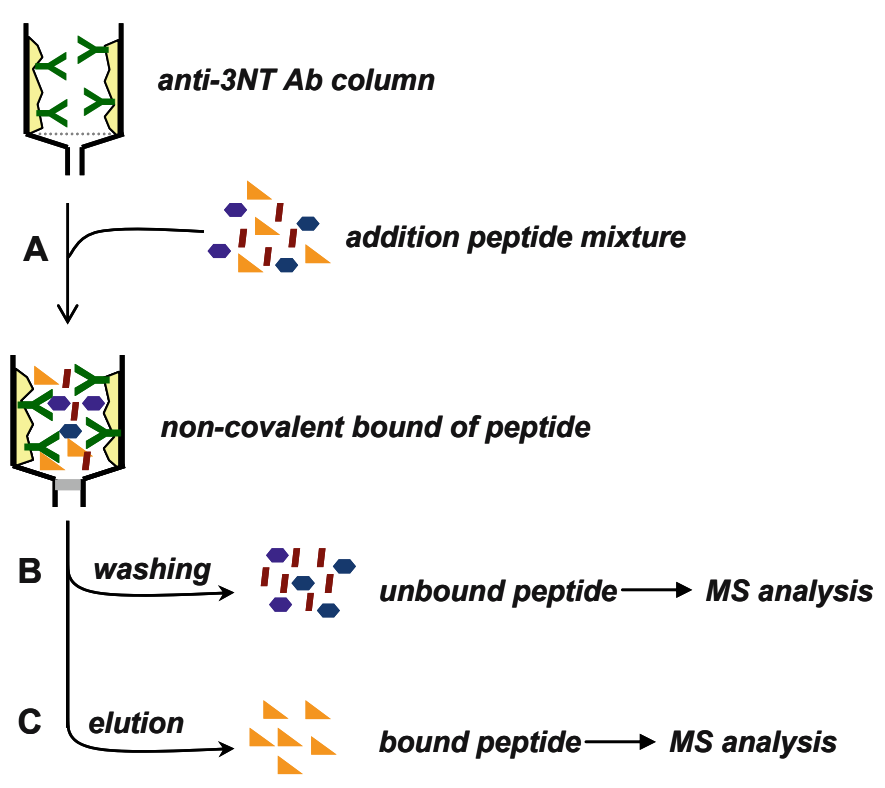

Figure 1. Schematic representation of an immuno-affinity experiment using immobilized antibody column. (A) Binding of peptides to the immobilized Ab column; (B) removal of unbound peptides; (C) dissociation of the antigen-antibody complex followed by washing steps and storage

\section{Materials and Methods}

\subsection{ANTIBODIES}

The anti-nitrotyrosine-antibodies employed in this work were obtained from Chemicon International (Bubendorf, Switzerland) and from Santa Cruz Antibodies (Santa Cruz, USA); characteristics of both antibodies as given by the anufacturers are summarized in Table 1.

The following commercially available reagents were used: N- $\alpha$-Fmoc-3Nitrotyrosine: Bachem (Bubendorf, Sitzerland); N- $\alpha$-Fmoc protected amino acids, NovaBiochem TGA (Darmstadt, Germany); benzotriazole-1-yl-oxy-tris-pyrrolidinophosphonium hexafluoro-phosphate (PyBOP): NovaBiochem; Roti ${ }^{\mathbb{B}}$-Block $(10 \times$ concentrate): Roth (Karlsruhe, Germany); ECL solution: Amersham Biosciences (München, Germany); activated CH-Sepharose 4B, poly-oxyethylenesorbitanmonolaureate (Tween20): Sigma (St.Louis, USA); $\alpha$-cyano-4-hydroxycinnamic acid (HCCA): Bruker Daltonics (Bremen, Germany). Water was taken from an in-house high purity water system (Milli Q plus, Millipore, 18.2 M 2 ). All reagents and solvents were of analytical grade or highest available purity. 
TABLE 1. Investigated monoclonal antibodies against 3-nitro-tyrosine

\begin{tabular}{|c|c|}
\hline Supplier & Antibody details \\
\hline Chemicon International (1) & $\begin{array}{l}\text { Mouse Anti-Nitrotyrosine Monoclonal Antibody } \\
\text { (MAB5404) } \\
\text { Concentration: } 1 \mu \mathrm{g} / \mu 1 \\
\text { Immunogen: Nitrated KLH (Keyhole-limpet hemocyanin) }\end{array}$ \\
\hline Santa Cruz (2) & $\begin{array}{l}\text { Mouse Monoclonal Nitrotyrosine (39B6) } \\
\text { Concentration: } 0.2 \mu \mathrm{g} / \mu \mathrm{l} \\
\text { Immunogen: } 3-(2-(4-\text { hydroxy-3-nitrophenyl)acetamido) } \\
\text { propionic acid-bovine serum albumin conjugate }\end{array}$ \\
\hline
\end{tabular}

\subsection{PEPTIDE SYNTHESIS}

The 3-nitro-Tyrosine and Tyrosine containing peptides were synthesised on a semiautomated peptide synthesizer (EPS-221, Intavis, Langenfeld, Germany) by SPPS, using Fmoc/t-butyl protection chemistry with all chemicals and reagents of analytical grade or highest available purity. To synthesise peptides with $\mathrm{C}$-terminal free carboxylate the TGA resin was employed with 40 min coupling and 5 min deprotection times in $20 \%$ piperidine solution in DMF.

\subsection{HPLC PURIFICATION}

Analytical RP-HPLC was performed on a BioRad (München, Germany) HPLC system using a $5 \mu \mathrm{m}$ Nucleosil $^{\circledR} 300-7 \mathrm{C}_{18}$ column as a stationary phase. Linear gradient elution of peptides dissolved in eluent $\mathrm{A}(20 \% \mathrm{~B}, 5 \mathrm{~min} ; 70 \% \mathrm{~B}, 55 \mathrm{~min})$ was performed with eluent A $(0.1 \%$ TFA in MilliQ water) and eluent B $(0.1 \%$ TFA in acetonitrile-MilliQ water $80: 20, \mathrm{v} / \mathrm{v}$ ) at a flow rate of $1 \mathrm{ml} / \mathrm{min}$. Peaks were detected at $365 \mathrm{~nm}$ for nitrated peptides and $220 \mathrm{~nm}$ for non-nitrated peptides. The crude products were purified on a $250 \times 20 \mathrm{~mm}$ preparative $\mathrm{C}_{18}$ column Grom-Sil 120 OSD-4 HE, $10 \mu \mathrm{m}$ (Grom, Herrenberg, Germany) at a flow rate of $10 \mathrm{ml} / \mathrm{min}$, using identical eluent conditions as for analytical HPLC.

\subsection{DOT BLOT ANALYSIS}

Peptide solutions of $1-2 \mu \mathrm{l}$ aliquots $(1 \mu \mathrm{g} / \mu \mathrm{l})$ in PBS $(\mathrm{pH}=7.4)$ were spotted on nitrocellulose (NC) membranes and dried for $5 \mathrm{~min}$ at room temperature. NC membranes were blocked for $2 \mathrm{~h}$ by using Roti ${ }^{\circledR}$-Block solution in Milli-Q water. Membranes were then probed for $1 \mathrm{~h}$ with mouse monoclonal antibody against 3nitro-tyrosine $(1: 2,500)$ in PBS-Tween buffer. The membranes were then washed three times in PBS-Tween buffer and probed again with a goat anti-mouse horseradish peroxidase conjugate (Sigman; 1:5,000) in PBS-Tween for 45 min. After washing the membrane five times in washing buffer, the immuno-positive spots were visualised by using ECL- Plus system (Amersham Pharmacia). 


\subsection{PREPARATION OF AFFINITY COLUMNS AND AFFINITY- MASS SPECTROMETRY}

The monoclonal anti 3-nitrotyrosine antibody $(100 \mu \mathrm{g} / \mu \mathrm{l})$ was dissolved in coupling buffer $\left(0.2 \mathrm{M} \mathrm{NaHCO}_{3}, 0.5 \mathrm{M} \mathrm{NaCl}, \mathrm{pH} 8.3\right)$. The solution was added to the appropriate amount of dry NHS-activated 6-aminohexanoic acid-coupled Sepharose $(1 \mathrm{~g}$ sepharose- swell in approximately $3 \mathrm{ml}$ of coupling buffer) and the coupling reaction was performed for $2 \mathrm{~h}$ at $25^{\circ} \mathrm{C}$ under vigorous stirring. The reaction mixture was then loaded into a micro-column and extensive washing steps $(0.2 \mathrm{M} \mathrm{NaOAc}$, $0.5 \mathrm{M} \mathrm{NaCl}, \mathrm{pH}=4.0)$ and blocking steps $(0.1 \mathrm{M}$ ethanolamine, $0.5 \mathrm{NaCl}, \mathrm{pH} 8.3)$ were carried out. Affinity experiments of the column prepared in this manner were performed by binding of the antigen peptides (solution prepared in PBS buffer, $\mathrm{pH}$ $=7.4$ ) to the antibody column and subsequent reaction for $2 \mathrm{~h}$. The unbound peptides were removed by washing steps using PBS buffer as described above, and the immune complex was dissociated by addition of $0.1 \%$ TFA (aqueous solution, $\mathrm{pH}=2$ ). The washing and elution fractions were collected, lyophilized, redissolved in $0.1 \%$ TFA and desalted using ZipTip procedure before MALDI-MS analysis.

MALDI-TOF (matrix assisted laser desorption-ionisation -time-of-flight) mass spectrometry was performed with a Bruker BiFlex-DE mass spectrometer equipped with a Scout MALDI source and video system, a nitrogen UV laser (337 nm), and dual channel plate detector. Sample preparation was performed with $0.7 \mu \mathrm{l}$ of a saturated solution of HCCA in acetonitrile $/ 0.1 \%$ TFA $(2: 1)$, which was mixed on the MALDI target with $1 \mu \mathrm{l}$ of the sample solution. Spectra were recorded at an accelerating voltage of $25 \mathrm{kV}$ and were averaged over forty single laser shots. Calibration was performed with a standard peptide mixture within an $\mathrm{m} / \mathrm{z}$ range, 1,000-5,000.

\subsection{ELISA}

All assays were performed in 96-well CovaLink-NH plates which were activated for $1 \mathrm{~h}$ using disuccinimidyl suberate (DSS) solution. After three times washing with distilled water, $100 \mu \mathrm{l} /$ well of the peptide solution (dilutions prepared in PBS buffer containing $5 \mathrm{mM} \mathrm{NaHPO}_{4}$ and $150 \mathrm{mM} \mathrm{NaCl}, \mathrm{pH}=7.4$ ) was added onto the plate and incubated over night. The non-specific adsorption sites were then blocked by treatment with $150 \mu \mathrm{l}$ blocking buffer for $1 \mathrm{~h}(0.1 \mathrm{M}$ ethanolamine). After washing steps, the plates were coated for $2 \mathrm{~h}$ at room temperature with $100 \mu \mathrm{l}$ of the monoclonal 3-nitrotyrosine antibodies (dilution 1:2,500). The wells were washed four times with $200 \mu \mathrm{l} /$ well of $0.05 \%$ Tween-20 (v/v) in PBS, and $100 \mu \mathrm{l}$ of peroxidase labelled goat anti-mouse IgG diluted 5,000 times in 5\% BSA was added to each well and incubated for $1 \mathrm{~h}$ at room temperature. The wells were washed three times with $200 \mu \mathrm{l} /$ well PBS-Tween and two times with $200 \mu \mathrm{l} /$ well $0.05 \mathrm{M}$ sodium phosphatecitrate buffer, $\mathrm{pH}=5,100 \mu \mathrm{l}$ of $o$-phenylenediamine dihydrochloride (OPD) in sodium phosphate-citrate buffer at $1 \mathrm{mg} / \mathrm{ml}$, and $2 \mu \mathrm{l}$ of $30 \%$ hydrogen-peroxide 
per $10 \mathrm{ml}$ of substrate buffer was added. After 5-10 min, the absorbance at $\lambda=490$ $\mathrm{nm}$ was measured on a Wallac 1420 Victor $^{2}$ ELISA Plate reader (Perkin Elmer, Boston, USA).

\section{Results and Discussion}

Two monoclonal 3-nitro-tyrosine antibodies (see Table 1) were characterised by dot blot, immunoaffinity chromatography - mass spectrometry and ELISA using different synthetic prostacycline synthase (PCS) peptides. A series of nitrated and non-nitrated tyrosine containing peptides within the domain PCS (419-432) were synthesised by SPPS as described in Materials and Methods. The use of 3-nitrotyrosine within the standard Fmoc and side-chain protection chemistry (t.-butyl, trityl) provided high coupling yields and homogeneities already for the crude peptides following deprotection. All peptides were subjected to final purification by preparative RP-HPLC (see Table 2) and characterised by MALDI-TOF mass spectrometry. The UV-MALDI -TOF mass spectra showed abundant molecular ions for all peptides and a series of specific photochemical fragmentations only in the case of the Tyr-nitrated peptides was observed. Peaks occurring with 16 and 32 mass units lower than those corresponding to the nitrated peptides resulted from products formed by prompt fragmentation caused by the immediate loss of oxygen from the nitro group to yield a nitroso species, followed by loss of second oxygen to form a nitrene- type ion, as previously described [19]. The mass spectrometric characterisation of nitrated peptides by high resolution MALDI-FTICR- MS enabled the detection of the specific photochemical decomposition products due to the nitro group in 3-nitrotyrosine containing peptides [14].

Dot blot is a straightforward, simple technique for peptide and protein detection in which the samples are spotted directly onto a membrane through circular templates. The method is based on the antigen-antibody recognition by using a first antibody against the membrane- immobilized antigen, and a second label-conjugated antibody for detection of the first antibody. The PCS peptides were spotted on a nitrocellulose membrane, and the unspecific sites were blocked with Roti ${ }^{\circledR}$-Block solution. After washing steps with PBS-Tween buffer, the membrane was incubated with anti-3-NT antibody for $1 \mathrm{~h}$ at room temperature. After further washing steps, a second enzyme-conjugated antibody (horse radish peroxidase (HRP) goatanti-mouse $\mathrm{IgG}$ ) which recognizes the Fc (crystallizable fragment) fragment of the first antibody was added and incubated for $45 \mathrm{~min}$. A mixture of ECLsolutions was added in order to develop the membrane and expose it on a film.

Figure 2 shows the dot blot binding responses of the 3-NT- antibodies to different PCS peptides. We observed that the MAB5404 (Chemicon; 1) gave an intense positive response only for the authentic Tyr-430 -nitrated peptide containing the actual Tyr-nitration site in PCS (see Figure 2A); the 39B6 antibody (Santa Cruz; 2) gave an intense response for the same peptide, however additional weaker positive 
TABLE 2. HPLC and MALDI-TOF-MS data of synthetic PCS peptides

\begin{tabular}{|c|c|c|c|c|}
\hline & $\begin{array}{l}\text { Peptide } \\
\text { code }\end{array}$ & - Sequence & $\begin{array}{l}\text { - HPLC } \\
- \text { retention } \\
\text { time }(\min )^{\mathbf{c}}\end{array}$ & $\begin{array}{l}- \text { MALDI-TOF }^{\mathbf{d}} \\
-\mathrm{m} / \mathrm{z}[\mathbf{M}+\mathbf{H}]^{+}{ }_{\text {calc/exp }}\end{array}$ \\
\hline & PCS-Y ${ }^{\mathrm{a}}$ & - DFYKDGKRLKNYSL-OH & -18.52 & $-\quad 1,746.91 / 1,747.72$ \\
\hline & $\mathrm{PCS}-\mathrm{NO}_{2}{ }^{\mathrm{a}}$ & - DFYKDGKRLKNY(NO $\left.\mathbf{N}_{2}\right) \mathrm{SL}-\mathrm{OH}$ & -18.37 & - $1,791.90 / 1,792.96$ \\
\hline & $\begin{array}{l}\text { PCS- } \\
\mathrm{NO}_{2}(\mathrm{RR})^{\mathrm{b}}\end{array}$ & - DFY(NO $\left.\mathbf{N}_{2}\right)$ KDGRRLKNYSL-OH & -20.11 & - $1,819.90 / 1,822.13$ \\
\hline & $\begin{array}{l}\text { PCS- } \\
\left.\mathrm{NO}_{2} \text { (Ala }\right)^{\mathrm{a}}\end{array}$ & - DFYKDGKRAAAAY $\left(\mathrm{NO}_{2}\right) \mathbf{A L}-\mathrm{OH}$ & -18.05 & - $1,633.79 / 1,634.71$ \\
\hline & PCS-F ${ }^{\mathrm{a}}$ & - DFYKDGKRLKNFSL-OH & -20.47 & - $1,730.92 / 1,732.71$ \\
\hline & $\mathrm{PCS}^{\mathrm{a}}$ & $-\mathrm{LKNY}\left(\mathbf{N O}_{2}\right)-\mathrm{NH}_{2}$ & -12.25 & $-581.64 / 582.97$ \\
\hline
\end{tabular}

${ }^{\mathrm{a}}$ Tyr-430 of Prostacycline synthase.

${ }^{\mathrm{b}} \mathrm{Tyr}-421$ of Prostacycline synthase, Lys ${ }^{425}$ was replaced by an Arg.

${ }^{c}$ RP-HPLC column: Vydac $C_{18}(250 \times 4 \mathrm{~mm}, 300 \AA$, $5 \mu \mathrm{m})$; $365 \mathrm{~nm}$ for nitro-Tyr containing peptides and $220 \mathrm{~nm}$ for Tyr/Phe containing peptides.

${ }^{\mathrm{d}}$ MALDI-TOF mass spectra were recorded with a Bruker Biflex ${ }^{\mathrm{TM}}$ linear TOF mass spectrometer.

responses were observed for the PCS peptide nitrated at Tyr-421 (3) and for the peptide (4) in which the amino acid residues around the nitrated Tyr-430 were replaced by alanine residues (see Figure 2B). Since no response was observed for the two non-nitrated Tyr- and Phe-containing peptides $(\mathbf{1}, \mathbf{5})$ of PCS (419-432) fragment, we can conclude that both antibodies show high specificity for nitrotyrosine.

(A)

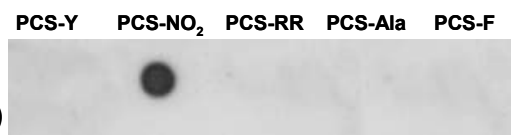

(B)

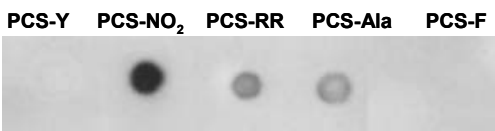

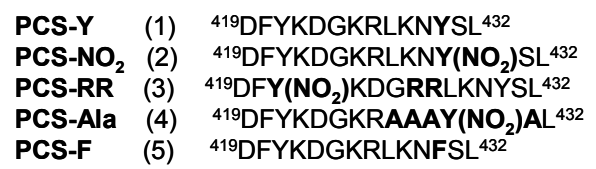

Figure 2. Dot blots analysis of (A) MAB5404 (Chemicon) antibody (1) and (B) 39B6 (Santa Cruz) antibody (2) to synthetic PCS (419-432) peptides

In order to ascertain the results of the dot blot experiments by a molecular recognition response, the 3-NT-antibody interactions were characterised by using the immunoaffinity- MS illustrated in Figure 1. Two antibody columns were prepared by coupling the mouse antibody MAB5404 (1) and the mouse antibody 39B6 (2) to NHS-activated Sepharose, as described in Materials and Methods. The PCS peptides were dissolved in PBS buffer, $\mathrm{pH} 7.4$ and added to the antibody columns. After $2 \mathrm{~h}$ incubation, the unbound peptides were removed, the column was washed 
several times with PBS buffer, and the peptide-antibody complexes were dissociated using $0.1 \%$ TFA. The first washing fractions containing unbound peptides, and the elution fractions which contain the peptides specifically bound to the 3-NT antibody column were collected, lyophilized and analysed by mass spectrometry.

Corresponding binding results for a mixture of the PCS (Y-430) (1) and the PCS-(Y(NO) $\left.)_{2}-430\right)$ peptide (2) to the monoclonal MAB5404 (Chemicon) antibody column (1) are shown in Figure 3. The affinity-mass spectrometric data showed that only the Tyr-430- nitrated PCS- peptide bound to the MAB5404 (Chemicon) antibody column. In contrast, affinity-MS experiments performed with several PCS (419-432) peptides that (i), contained a nitration site at Tyr-421, or (ii) contained an alanine sequence adjacent to the Tyr- 430 residue did not show binding affinity. These results suggest high recognition specificity for this nitration site that had been shown previously to cause specific inactivation of prostacyclin synthase upon treatment with peroxynitrite [13].

Furthermore, these results indicate that the affinity of the MAB5404 antibody (1) (raised against nitrated keyhole limpet hemocyanin carrier protein) is not merely directed by a nitrated tyrosine residue, but also by a recognition sequence encompassing amino acid adjacent to the nitration site.

Somewhat different results regarding a possible sequence-specific motif for recognition of nitro-Tyrosine were obtained for the 39B6 (Santa Cruz) antibody (2). The affinity-mass spectrometry data for this antibody generally showed binding affinity for the nitrated PCS peptides, consistent with the results obtained by the dot blot experiments. In order to compare the binding in affinity-MS analyses, equimolar mixtures $(200 \mu \mathrm{mol})$ of nitrated PCS peptides were applied to the 3-NT antibody column. The MALDI- mass spectrum of the elution fraction of the equimolar mixture of nitrated Tyr-430 PCS peptides 2 and $\mathbf{4}$ (see Figure 4) showed affinity for both peptides, albeit with lower affinity for the peptide containing the

(1) DFYKDGKRLKNYYSL-OH $[\mathrm{M}+\mathrm{H}]^{+:}: 1745,91$

(2) DFYKDGKRLKNY $\left(\mathrm{NO}_{2}\right) \mathrm{SL}-\mathrm{OH} \quad[\mathrm{M}+\mathrm{H}]^{+}: 1791,90$

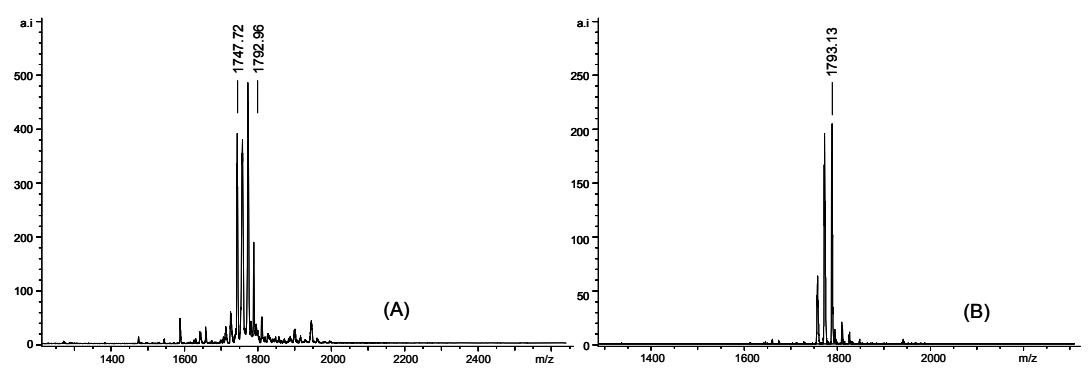

Figure 3. Affinity-mass spectrometry analysis of PCS (419-432) peptides 1 and 2 (nitrated at Tyr-430) with the monoclonal antibody MAB5404 (1); MALDI-TOF-MS of the washing (A) and elution (B) fractions. 
alanine-sequence mutation adjacent to the nitration site. Similar results with the 39B6 antibody (2) column were obtained by affinity-MS of PCS peptides nitrated at different Tyr residues, such as using peptide 3. Thus, the elution fraction of an equimolar mixture of nitrated Tyr-430 PCS-Ala (4) and nitrated PCS-RR (3); nitroTyr-421) indicate comparable affinities for both peptides (see Figure 5).

The binding affinity observed was significantly lower than that of the Tyr-430 nitrated peptide 2; however, due to the photochemical decomposition of the nitro group in Tyr-nitrated peptides under UV-MALDI-MS conditions, no quantitative determination was carried out from the mass spectrometric data.

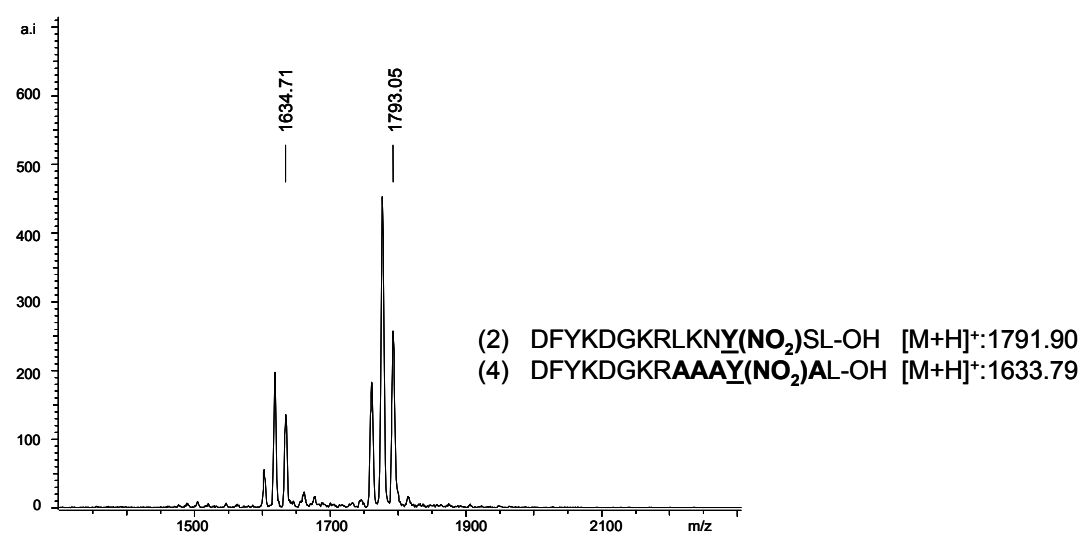

Figure 4. Affinity-mass spectrometry analysis: (MALDI-TOF-MS of elution fraction) of the nitrated Tyr-430 PCS- peptides 2 and 4 to the 39B6 antibody (2)

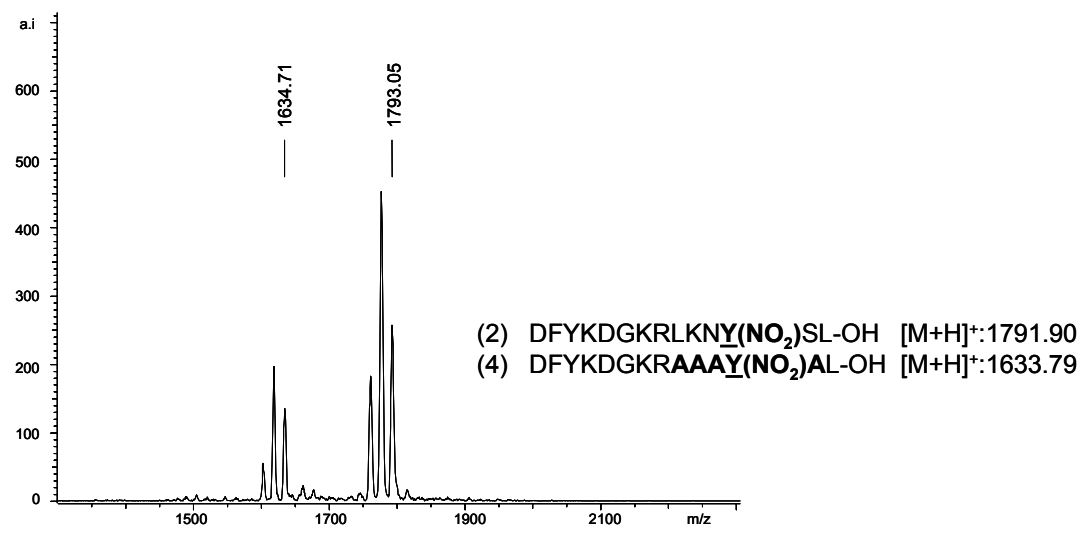

Figure 5. Affinity-mass spectrometry analysis: (MALDI-TOF-MS of elution fraction) of the mutated Tyr-nitrated peptides PCS-Ala (4) and nitrated Tyr-421 containing peptide, PCS-RR (3) with the 39B6 antibody (2) 
A quantitative estimation of the bindining affinities of the PCS peptides was performed by ELISA as an established technique for comparison of biomolecular affinities. In this study, only a comparative semi-quantitative analysis was aimed at, with regard to the observation that antibody binding may be influenced by a hindered of access of 3-nitrotyrosine residues, and by the structural environment of a nitro-tryosine motif [10]. Corresponding ELISA experiments with the two antinitrotyrosine antibodies are compared in Figure 6 for the series of nitrated PCS peptides. Due to the substantial differences in surface adsorption of small peptides, and to minimize unspecific adsorption, covalent attachment was employed with CovaLink-NH plates [20], in which a polystyrene surface is grafted with secondary amino groups to orientate the immobilized peptide on the surface in order to expose the epitope. In a first step of the ELISA determination, the NH-linker was activated using an excess of disuccinimidyl suberate (DSS) and then the diluted peptides solution was added and incubated overnight.

After suitable washing and blocking steps, the CovaLink-NH plate was then incubated with the anti- 3-NT antibody, and horse radish peroxidase (HRP) goat anti-mouse $\mathrm{IgG}$ was used as a detection antibody with $\mathrm{OPD} / \mathrm{H}_{2} \mathrm{O}_{2}$ used as the substrate for HRP as described in Materials and Methods. For comparison of the affinities of the PCS peptides, the concentrations needed for obtaining an $\mathrm{OD}_{450}=1$ were determined (see Figure 6).

According to the ELISA data with the MAB5404 antibody (see Figure 6A), only the Tyr-430 nitrated PCS- peptide 2 showed significant affinity to this antibody (lowest amount of PCS-NO $\mathrm{NO}_{2}$ peptide to obtain an $\mathrm{OD}_{450}=1: 0.37 \mu \mathrm{M}$ ). This result is consistent with the affinity-MS data and confirmed the requirement of a specific sequence motif around the 3-nitrotyrosine for antibody interaction. Thus, sequence mutation by alanine residues adjacent to the Tyr-430 nitration site, and change of the nitration position (Tyr-421), resulted in drastically diminished antibody binding. In contrast, the 39B6 antibody revealed significant binding for all nitrated PCS peptides (Figure 6B). The results of the ELISA determinations revealed some differences to the affinity-mass spectrometric analyses in which the Tyr-430 nitrated PCS-peptide (2) showed lower affinity than the alanine-mutated peptide $\mathbf{4}$ (lowest amount of PCS- $\mathrm{NO}_{2}$ peptide to obtain an $\mathrm{OD}_{450}=1: 0.095 \mu \mathrm{M}$ ). This effect might be explained by the increase in hydrophobicity introduced by the alanine mutation causing increased exposure of the nitrated Tyr-430. In the ELISA determination with the 39B6 antibody (2), significant affinity was also found for the short, nitrated PCS tetra-peptide, PCS (427-430) fragment which was not detected with the MAB5404 antibody (1).

The differences found in binding affinities of Tyr-nitrated peptides by affinitymass spectrometry in comparison to dot blot and ELISA determinations, may be attributed to the different types of antigens used for producing the anti-3-NT antibodies have been raised. Thus, the 39B6 antibody (Santa Cruz) was raised against a 3-(2-(4-hydroxy-3-nitrophenyl) acetamido) propionyl-bovine serum albumin conjugate in which the (4-hydroxy)-3-nitrophenyl group is more exposed and freely accessible, compared to the nitrotyrosine residue in the polypeptide chain of 

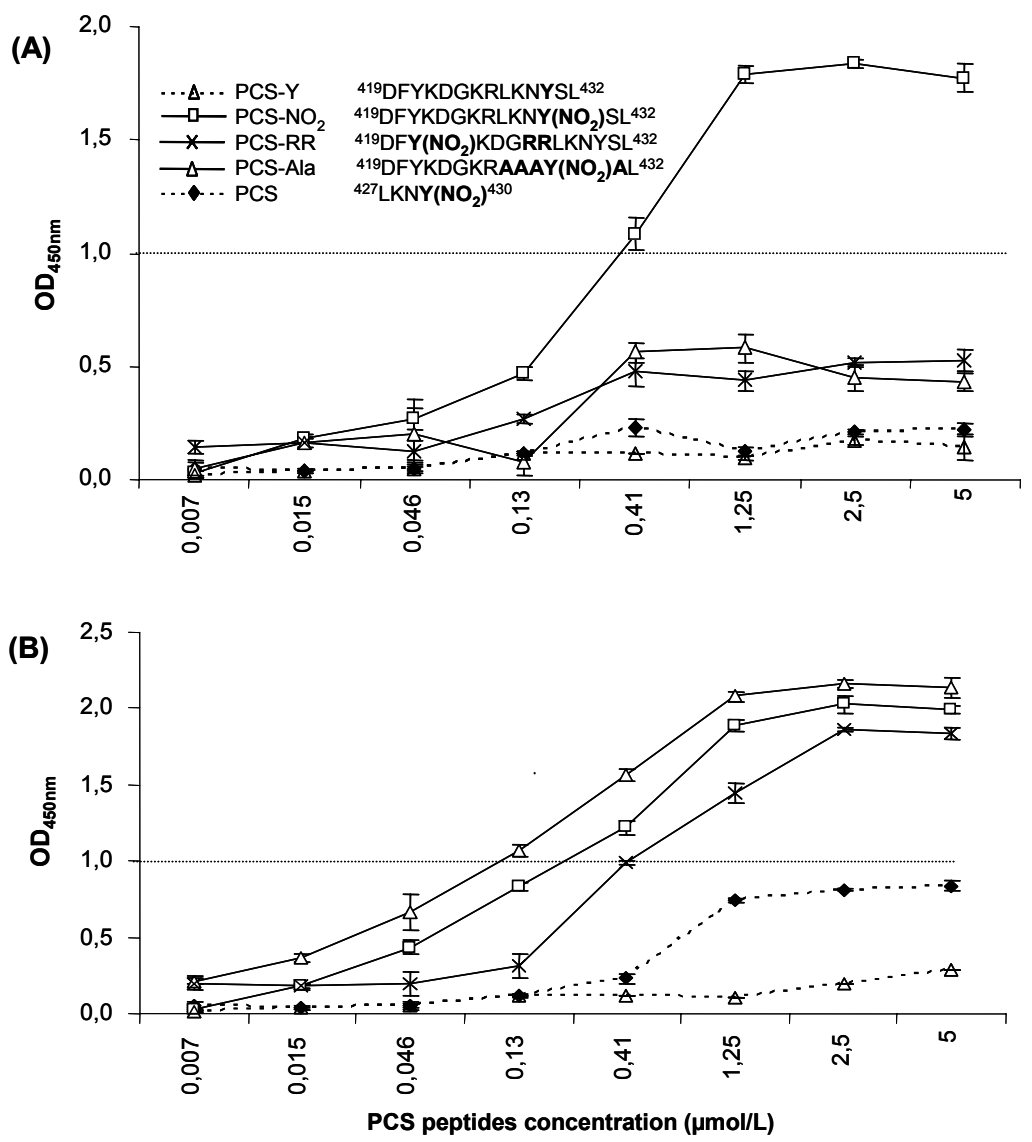

Figure 6. ELISA determination of the binding of the MAB5404 (Chemicon) antibody (A) and the 39B6 (Santa Cruz) antibody (B) to synthetic prostacycline synthase peptides

the nitrated KLH (Keyhole-limpet hemocyanin) carrier protein, employed as antigen for the MAB5404 (Chemicon) antibody. Hence, the 39B6 antibody showed generally high affinity to single 3-nitrotyrosine amino acid residues, in contrast to the epitope-peptide sequence motif determining the recognition specificity of the MAB5404 antibody. This recognition motif has been recently characterised in our laboratory to require a set of positively charged residues (Lys, Arg) at the Nterminal adjacent to the nitrotyrosine residue (Dragusanu et al.; J. Peptide Sci., submitted for publication).

\section{Conclusions}

In complementing the conventional immuno-analytical techniques such as dot blot and ELISA, affinity- mass spectrometry is shown in this study as a powerful, 
molecular tool for characterising recognition specificities of antibodies, especially for protein structure modifications such as tyrosine nitration. The comparison of the three methods essentially provided consistent results to reveal differences in binding affinities and specificities by the anti-nitrotyrosine antibodies, suggesting that antibody binding may be influenced by the peptide structure adjacent to the nitrotyrosine modification. The capability of anti-nitrotyrosine antibodies to discriminate between nitrotyrosine in different environments in proteins may be useful for producing antibodies to specific motifs containing tyrosine residues, and for the development of highly specific biomarkers.

\section{Acknowledgments}

We thank Dr. Markus Bachschmid for expert help and suggestion in using the CovaLink-NH ELISA plates. This work has been partially supported by the DFG (FG-753) and the University of Konstanz.

\section{References}

1. Brennan ML, Wu W, Fu X, et al. (2002) A tale of two controversies: defining both the role of peroxidases in nitrotyrosine formation in vivo using eosinophil peroxidase and myeloperoxidase-deficient mice, and the nature of peroxidase-generated reactive nitrogen species. $J$ Biol Chem 277: 17415-17427.

2. Hopkins N, Cadogan E, Giles S, Bannigan J, McLoughlin P. (2003) Type 2 nitric oxide synthase and protein nitration in chronic lung infection. J Pathol 199: 122-129.

3. Petersson AS, Steen H, Kalume DE, Caidahl K, Roepstorff P. (2001) Investigation of tyrosine nitration in proteins by mass spectrometry. J Mass Spectrom 36: 616-625.

4. Ischiropoulos H. (2003) Biological selectivity and functional aspects of protein tyrosine nitration. Biochem Biophys Res Commun 305: 776-783.

5. Good PF, Hsu A, Werner P, Perl DP, Olanow CW. (1998) Protein nitration in Parkinson's disease. J Neuropathol Exp Neurol 57: 338-342.

6. Castegna A, Thongboonkerd V, Klein JB, Lynn B, Markesbery WR, Butterfield DA. (2003) Proteomic identification of nitrated proteins in Alzheimer's disease brain. $J$ Neurochem 85: 1394-1401.

7. Turko IV, Li L, Aulak KS, Stuehr DJ, Chang JY, Murad F. (2003) Protein tyrosine nitration in the mitochondria from diabetic mouse heart. Implications to dysfunctional mitochondria in diabetes. J Biol Chem 278: 33972-33977.

8. ter Steege J, Buurman W, Arends JW, Forget P. (1997) Presence of inducible nitric oxide synthase, nitrotyrosine, CD68, and CD14 in the small intestine in celiac disease. Lab Invest 77: 29-36.

9. Hinson JA, Michael SL, Ault SG, Pumford NR. (2000) Western blot analysis for nitrotyrosine protein adducts in livers of saline-treated and acetaminophen-treated mice. Toxicol Sci 53: 467-473.

10. Khan J, Brennand DM, Bradley N, Gao B, Bruckdorfer R, Jacobs M. (1998) 3-Nitrotyrosine in the proteins of human plasma determined by an ELISA method. Biochem $J$ 330(Pt 2): 795-801. 
11. Franze T, Weller MG, Niessner R, Poschl U. (2003) Enzyme immunoassays for the investigation of protein nitration by air pollutants. Analyst 128: 824-831.

12. Franze T, Weller MG, Niessner R, Poschl U. (2004) Comparison of nitrotyrosine antibodies and development of immunoassays for the detection of nitrated proteins. Analyst 129: 589 596.

13. Schmidt P, Youhnovski N, Daiber A, et al. (2003) Specific nitration at tyrosine 430 revealed by high resolution mass spectrometry as basis for redox regulation of bovine prostacyclin synthase. $J$ Biol Chem 278: 12813-12819.

14. Petre BA, Youhnovski N, Lukkari J, Weber R, Przybylski M. (2005) Structural characterisation of tyrosine-nitrated peptides by ultraviolet and infrared matrix-assisted laser desorption/ ionisation Fourier transform ion cyclotron resonance mass spectrometry. Eur J Mass Spectrom (Chichester, Eng) 11: 513-518.

15. Suckau D, Kohl J, Karwath G, et al. (1990) Molecular epitope identification by limited proteolysis of an immobilized antigen-antibody complex and mass spectrometric peptide mapping. Proc Natl Acad Sci USA 87: 9848-9852.

16. McLaurin J, Cecal R, Kierstead ME, et al. (2002) Therapeutically effective antibodies against amyloid-beta peptide target amyloid-beta residues 4-10 and inhibit cytotoxicity and fibrillogenesis. Nat Med 8: 1263-1269.

17. Macht M, Marquardt A, Deininger SO, Damoc E, Kohlmann M, Przybylski M. (2004) "Affinity-proteomics": direct protein identification from biological material using mass spectrometric epitope mapping. Anal Bioanal Chem 378: 1102-1111.

18. Stefanescu R, Iacob RE, Damoc EN, et al. (2007) Mass spectrometric approaches for elucidation of antigenantibody recognition structures in molecular immunology. Eur J Mass Spectrom (Chichester, Eng) 13: 69-75.

19. Sarver A, Scheffler NK, Shetlar MD, Gibson BW. (2001) Analysis of peptides and proteins containing nitrotyrosine by matrix-assisted laser desorption/ionization mass spectrometry. J Am Soc Mass Spectrom 12: 439-448.

20. www.nuncbrand.com. 